\title{
Impact of Muga Silk (Antheraea assamensis) on Community Livelihood in the Brahmaputra Valley of Assam-India
}

\author{
Niranjan Das \\ Department of Business Administration, Tezpur University, Napaam, Sonitpur-Assam, India
}

Email address:

das_niranjan2002@yahoo.com,niranjan@tezu.ac.in

\section{To cite this article:}

Niranjan Das. Impact of Muga Silk (Antheraea assamensis) on Community Livelihood in the Brahmaputra Valley of Assam-India. American Journal of Environmental Protection. Vol. 10, No. 3, 2021, pp. 59-65. doi: 10.11648/j.ajep.20211003.11

Received: March 24, 2021; Accepted: May 29, 2021; Published: June 7, 2021

\begin{abstract}
Muga the golden-yellow silk produced by 'Antheraea assama' is found only in the Brahmaputra Valley of AssamIndia. This species of silkworm is semi-domesticated in that the rearers collect the worms that crawl down at the end of their larval period. They are allowed to spin cocoons in the rearer's houses. The gleaming golden yellow silk is referred to in literature from as long as $1662 \mathrm{BC}$. The 'Antheraea assamensis' is cultivated especially in Brahmaputra valley because it's characteristic ecological requirements are found only in its natural abode. The declines of Som (Machilus bombycina), Soalu (Litsaea ppolyantha) plantation areas in rearing and sericulture farms have pushed Muga silk towards the verge of extinction. Encroachment in government Som plantation (host plant) areas is one of the prime causes of decreasing food availability of Muga silk worm. If measures are not taken the Muga (Antheria assamensis) heritage of Assam may face extinction in the near future. Considering the ecological conditions, food plant distribution, presence of eco-types and species of diverse nature in coexistence, it is speculated that this region is a possible home of origin of Antheraea. In this paper the researcher emphasizes the possibility of sustaining community livelihood in the Brahmaputra valley of Assam, India.
\end{abstract}

Keywords: Muga, Natural Silk, Environment Conservation, Sustainability and Livelihood

\section{Introduction}

The Muga silk rearing is confined to the North-East India, particularly, the Brahmaputra valley of Assam. This is perhaps, due to pleasant climatic conditions and distribution of wide range of muga host plants in this region [14]. In Assam 'Som' tree provides the principal food for muga silkworms which produce the golden coloured silk that is very specific and prestigious to Assam particularly in the Brahmaputra valley of India and found nowhere else on the globe [5]. The state of Assam is a center of diversity for som tree with rich source of genetic diversity and it is reservoir of valuable gene pool [13]. The cultivation of som tree under diverse agro-ecological conditions for a continuous period under various biotic and abiotic stresses, specific adaptation through natural selection and farmers discretion over years have resulted, introduction of different types of som cultivars into the region leading to further diversification of the som genetic stock [11]. Traditionally, the farmers of Assam had classified the som plants into four types on the basis of leaf shape locally known as Naharpatia, Ampatia, Jamupatia and Kathalpatia of which Naharpatia is considered as the best [2]. The land races are genetically diverse and heterogeneous population. The land races are genetic resources for the development and improvement of modern varieties. These land races are reported by several workers [9].

\section{Geographical Distribution of Muga Silk}

Fossil's evidence indicates that the genus Persea originated in West Africa during the Paleocene era (geologic period from $65.5 \pm 0.3$ to $55.8 \pm 0.2$ million years ago) and spread to Asia, Europe, South America and then to North America. It is thought that the gradual drying of Africa, West Asia and the Mediterranean from Oligocene era (geologic period from about 33.7 to 23.8 million years ago) to the Pleistocene era (from 1.8 to 11,550 million years ago) and 
the glaciations of Europe during the Pleistocene caused extinction of the genus across these regions, resulting in present disjunctive distribution.

The genus Persea belonging to family Lauraceae has about 70 Neotropic species, ranging from Brazil and Chile in South America to Mexico, West Indies and South-Eastern United States in North America. A single species Persea indica is endemic to the Macaronesian Island including Madeira and the Canary Islands; nearly 80 species in East and South-East Asia [3] ranging from outer Himalayan ranges in Pakistan and India to Sikkim, Burma, Java, Sumatra, China and to Ceylon. In India, Persea is found up to an elevation of 8000 feet above mean sea level along the lower Himalaya from Garhwal and Kumaon Hills to Sikkim, Khasi and Jaintia Hills, Assam and to tropical wet evergreen forest of Arunachal Pradesh [16].

The best known Persea species is the Persea Americana (Avacado) widely cultivated in subtropical regions for its large, edible fruit. Whereas, in India especially in NorthEastern region Persea bombycina (King ex Hook f.) Kosterm. (Som) as the host plant of muga silkworms (Antherea assamensis, Helfer) is economically most important [18]. It grows throughout Assam both in natural and cultivated form, ascending to an elevation of about 1500 $\mathrm{ft}$ in the Khasi and Jaintia Hills of Meghalaya and along with pine and oak forest of Garhwal and Kumaun hills region up to the altitude of 1500 meter above mean sea level [19]. It also grows along the lower Himalaya as far as west Nepal.

\subsection{Muga Host Plants and Their Distribution}

Muga silkworms' food plants grow well in high rain fall, humid and warm climatic conditions in Assam. Most of the muga food plants belong to the family Lauraceae (orderLaurales) [15]. The species occur in natural condition in subHimalayan hill range particularly in the north-astern India [6] The food plant of western and sub-Himalayan belts is variable and show different morph metric characters with those of Assam, Arunachal Pradesh, Meghalaya and Mizoram [7]. Among the different food plants, som Persea bombycina (King ex Hook.f) Kostern is principal food plant of muga silkworms (Antheraea assamensis Helfer). Thangavalu et al., 1988 have reported 11 species as food of muga silkworms. Tikader (2010) reported 19 species as food plants of muga silkworms, among which Zizyphus jujube, Zizyphus maririana, Gmelina arboraea, Michelia champaca, Michelin oblonga, Symplocos paniculata, Symplocos grandiflora, Symplocos ramosissima, Zanthoxylum armarum and Zanthoxylum limonella are the most common species. These species are broadly classified into primary, secondary and tertiary food plants on basis of feeding preference of silkworms [19]. The distribution pattern of muga silkworm's food plants is given in the following table.

Table 1. Geographical Distribution of Muga Silkworms Host Plant Species.

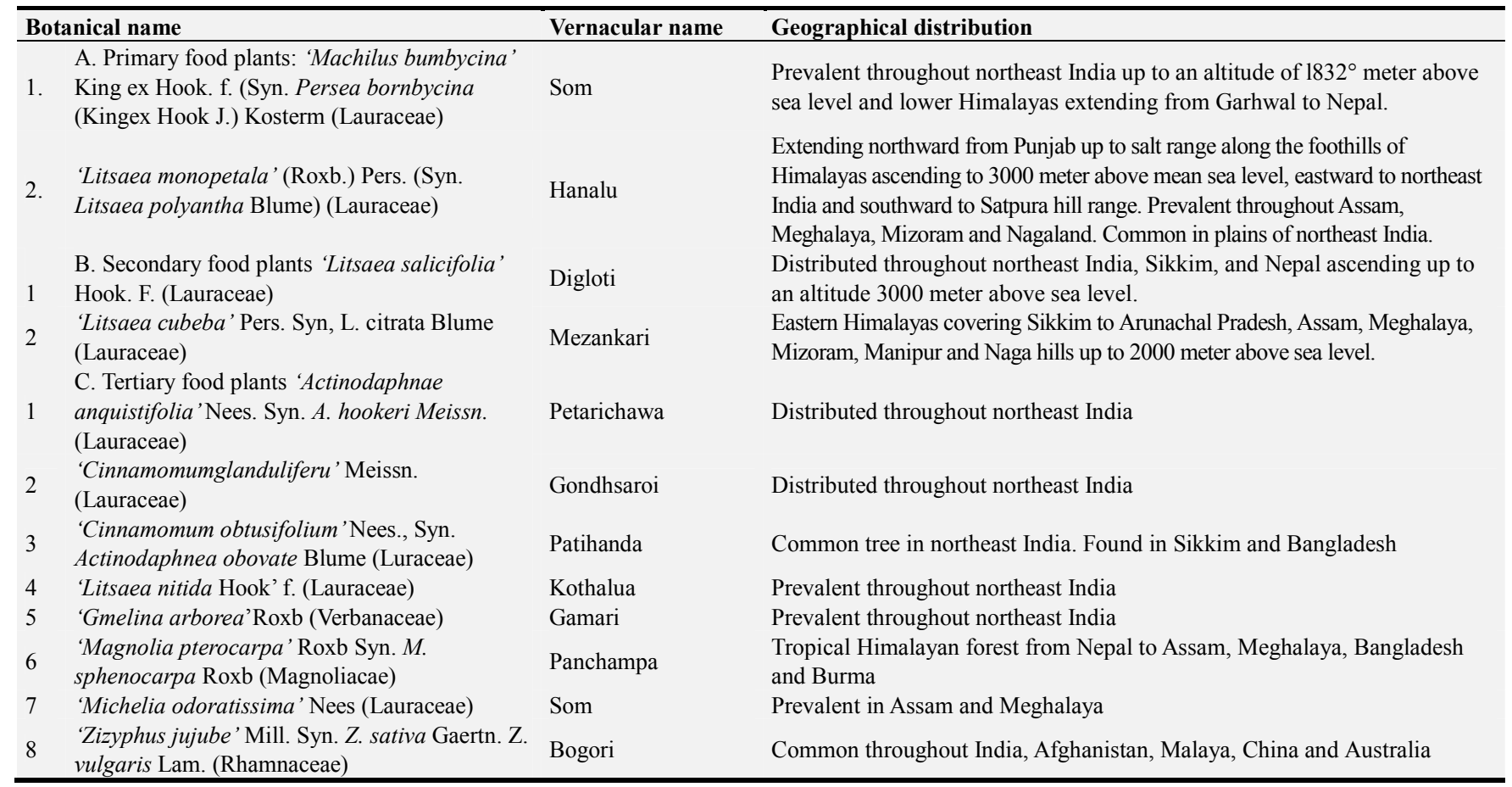

Source: Present status and constraints of muga silkworm host plant germplasm conservation: Neog K, Gogoi SN, Chakravorty R (2015)

Muga silkworm's host plants grow in natural habitats and enrich the genetic resources and diversity of species. Eri silkworm is polyphagous in nature and feeds on number of food plants. These host plant species are 'Ricinus communis' L. (Castor), Family: Euphorbiaceae, 'Manihot esculanta'
Crantz. (Cassava/Tapioca), Family: Euphorbiaceae, 'Sapium eugeniifolium' Buch- Ham (Korha), Family: Euphorbiaceae, 'Evodia fraxinifolia' Hook (Payam), Family: Rutaceae, 'Alianthus grandis' Prain (Barpat), Family: Simaroubaceae, 'Ailanthus excels' Roxb. (Barkesseru), Family: 
Simaroubaceae, 'Plumeria acutifolia' Poir (Gulanch), Family: Apocynaceae, 'Heteropanax fragrans' (Roxb.) Seem (Kesseru), Family: Araliaceae, 'Jetropa curacus' L. (Bhotera), Family: Euphorbiaceae and 'Gmelina arborea' (Gamari), Family: Verbanacae grow natural habitats in this region.

\subsubsection{Som (Machilus bombycina) as Principal Host Plant of Muga Silkworms}

Som is the principal host plant of Muga silk worms, 'Antheraea assamensis Helfer' and widely distributed in northeast India. Muga is a golden yellow silk produced by silk moth a semi-domesticated sericigenous insect species endemic to Brahmaputra valley of Assam. It is semidomesticated owing to the fact that the larval stage is spent in the open and ripening worms are brought indoor for spinning the cocoons and conducting grainage for dfls (Disease Free Laying's) production [20]. Traditionally, the seed cocoons intended for preparation of eggs are kept in a single layer in trays or 'Khang' (basket) to facilitate the emergence of the moths. Moths emerge from the cocoons in the evening and pair in the bamboo tray or 'Khang' itself mating is allowed during the night. Next morning, the mated females are separated and tied with a piece of cotton threaded to a 'Kharika' (a roll of straw with a hook) on which they lay eggs about 150-250 eggs on the 'kharika'. The eggs are brown. The reare's take the 'khorikas' with hatched worms and hang them on the host plant. Lose eggs are prepared also and packed into paper or cloth bags for distribution.

\subsubsection{Traditional Ways of Muga Rearing During a Seasons}

Muga silkworm culture is a traditional outdoor rearing practice and adopted by people of Assam states particularly Brahmaputr valley [21]. It is polyphagias, multivoltine reared in six different seasons throughout the year. Out of these six seasons two seasons namely, May-June and October-November are commercial crop seasons, whereas, other seasons are seed crop seasons. Again, the seed crops during December-January and June-July are called pre-seed crop. Thus, each commercial crop is preceded by one pre-seed crop and one seed crop. Since, this pattern of muga silkworm's cultivation has been an age-old practice, it is obviously environment controlled and the rearing performance is quite different in each season Nodal and. Hence, effecting rate of rearing in each season shows wide variation in different seasons due to lack of improved breeds in muga. Muga silkworms belong to the Lepidoptera of Saturniidae family and, geographically are located only to northeastern region of India. Geographical isolation of this silkworm is indicative of its special requirements for geo-climatic conditions that prevail in this region, that is, high humid temperate climate and forest vegetation of primary and secondary host plants [4]. Thus, this species is phylogenetically less adaptive reaching its ecological isolation that is indicative of being on verse of extinction and urgent required in-situ conservation [1]. Although, Muga silkworm since time immemorial has been reared for muga silk still it is purely an outdoor culture on host plant under natural conditions. Only cultural specificity is being managed and took care by muga rearer. Being exposed to natural environment muga culture practices encounter lots of problems right from brushing of worms to spinning of cocoons. Outdoor silkworm's larvae are invariably expose 'to nature's vagaries such as seasonal climate change, rainfall and strong wind, solar temperature, besides pests, predators and pathogens inflecting heavy loss particularly in early three instars [8]. Prophylactic measures adopted for pest and diseases in outdoor rearing became fruitless due to cross infestation by both pests and pathogens are common in open conditions. Sengupta reported that more than 50 per cent worms was lost during summer due to abiotic factors and 80 per cent of total loss of muga silkworms occurred in second and third instars only [10]. Although, a number of farmers' friendly new technologies have been innovated [12] for the development of muga industry to enhance the muga silk production, still production of cocoon per dfl in different season is far away to meet demands of consumers, in the region. It is very essential to develop new technologies especially new improved host plant varieties to increase the raw silk production in the muga growing states.

\subsection{Som and In-situ Conservation of Muga Silk (Antheraea Assamensis Helfer)}

Muga silkworms show diversity within the species which indicate the possibility of isolation of new inbreed lines and development hybrid in the species. Although, the species shows heterozygous nature, there is no any improved muga silkworms breeds for commercial exploitation [16] Nodal. As old aged traditional practices of Ahom Kings, seeds were collected preferably from forests of Garo Hills through rearing in jungle in In-situ habitats which was further multiplied as commercial crop in valley during Kotia (October-November) and further multiplied through selection breeding in pre seed crop (December-January) and seed crops (February-March) till Jethewa (April-May) commercial crop where, bumper cocoons were harvested. The historic muga crop management practices of Ahom kings indicated the needs of In-situ conservation of muga silkworms and improvement of breeding strategies. The breeding of muga silkworms from P4 stock to Pl stock is directly correlated with dfl (Disease Free Layings) production systems which need details investigation and standardization of breeding technologies of species. Thangavalu (1988) reported muga management system from P-4 stock (seed rearing) to P-1 stock (commercial rearing), it indicates the modification due to changes of global climates and rapid deforestation in northeastern states of India [16].

Muga silkworm's shows heterozygous natures in wild conditions and after 5-6 successive generations develop homozygous nature and lose the vigor and heterosis due to genetic drift and inbreeding depression. The cultivated lines of 'Antheraea assamensis' cannot be utilized as parents' materials in P-4 stock for multiplication in P-3, P-2 and P-1 stock for seed production and commercial cocoon production. Presently, the silkworms breeding technologies in seed production system of muga silkworms, P-4 parent resources are collected from the farmers' field due to lack of germplasm or improved breeds in the species. Muga 
silkworm's loss their heterozygous character in Ex-situ conditions which indicate the necessity of conservation of muga in natural habitats to continue heterozygous nature. Som can play significant role in conservation of muga silkworms in natural habitats for evergreen nature [18]. The species should be extensively planted in the forest, national parks, and reserve forest hence standard model for plantation is essential for the species.

\section{Economics of Muga Silk Rearing}

Sericulture is one of the most important crops where minimum investment is required with maximum return. Rupees 58,552/- can be generated from 1 acre of som plantation through silkworms rearing using paid labours. On the other hand, Rs 83,392/- can be earned using labours from 1-acre som plantation within a year. Details of economics of som plantation and silkworms rearing are discussed below.

Table 2. Initial Establishment Cost of 1 (One) Acre of Som Plantation.

\begin{tabular}{|c|c|c|c|c|c|c|}
\hline SI No & Particulars & Input & Man days & Rate (Rs.) & Amount (Rs.) & Remarks \\
\hline 1. & Land preparation by Tiller & - & 3 & 500 & 1500 & \\
\hline 2. & Uprooting of trees, removing roots and leveling plot & - & 15 & 300 & 4500 & \\
\hline 3. & Pit digging@50/man day & - & 10 & 300 & 3000 & \\
\hline 4. & FYM application/Manuring of pit & & 8 & 300 & 2400 & \\
\hline 5. & Seedling cost & 800 & & 3 & 2400 & \\
\hline 6. & Seedlings Transplantation & - & 8 & 300 & 2400 & \\
\hline 7. & Cost of FYM & $4 t$ & & 1550 & 6200 & \\
\hline 9. & Cultural operation & - & 22 & 300 & 6600 & \\
\hline 10 & Urea $(\mathrm{Kg})$ & $70 \mathrm{~kg}$ & & 22 & 1540 & After 6 \\
\hline 11. & $\mathrm{SSP}(\mathrm{Kg})$ & $90 \mathrm{~kg}$ & & 15 & 1350 & months of \\
\hline 12. & MOP (kg) & $50 \mathrm{~kg}$ & & 25 & 1250 & growth \\
\hline 13. & Fungicide/insecticides & $10 \mathrm{~kg}$ & & 500 & 5000 & \\
\hline 14. & Bamboo fencing & 30 & & 120 & 3600 & \\
\hline 15. & Miscellaneous & & & - & 1000 & - \\
\hline
\end{tabular}

Source: Collected and computed by researcher from field, 2019

Table 3. Annual Expenditure for 1 Acre of Som plot per year from 2-4 year of growth.

\begin{tabular}{llllll}
\hline SI & Item & Input & Man days & Rate (Rs.) & Amount (Rs.) \\
\hline 1. & & & & Amount (Rs.) \\
2. & Part of initial cost & & $8 \%$ pa & - \\
3. & Repayment of bank interest & & 12 & 300 & 3600 \\
4. & Digging \& weeding & $4 \mathrm{t}$ & & 3000 & 12000 \\
5. & Cost of cow dung & $150 \mathrm{~kg}$ & & 22 & 3300 \\
6. & Cost of SSP & $170 \mathrm{~kg}$ & & 18 & 3060 \\
7. & Cost of MOP & $60 \mathrm{~kg}$ & & 25 & 1500 \\
8. & Application of items at 3 to 7 & & 300 & 4500 \\
9. & Insecticide \& pesticide & & & 1000 \\
10. & Miscellaneous & & & 1000 \\
& Total $=$ & 27 & & Rs. 32,160 \\
\hline
\end{tabular}

Source: Collected and computed by researcher from field, 2019

An expenditure of Rs. 15,416 has to be incurred per year from $2-4^{\text {th }}$ year growth of plantation to conduct 1000 dfls per year in $5^{\text {th }}$ year growth of plantation. Hence, Rs. 15,416.00 is considered for calculation of economics.

Table 4. Initial Investment on Silk Worm Rearing Based on 1 Acre of Som Land.

\begin{tabular}{llllll}
\hline SI & Item & Quantity & Amount (Rs.) & Longevity (years) & Depreciation/Year (Rs.) \\
\hline 1. & Jali house for silkworms & 1 No. & 25000 & 5 & 5 \\
2. & Worms transfer chalani & 50 Nos. & 17500 & 5 & 1750 \\
3. & Jali stands & 10 Nos. & 2000 & 10 & 100 \\
4. & Knife & 1 No & 100 & 10 & 10 \\
5. & Hygrometer & 1 No. & 400 & 10 & 10 \\
6. & Bamboo pachi/plastic container & 10 Nos. & 1500 & 10 & 1500 \\
7. & Sprayer machine & 1 No. & 15000 & 5 & 150 \\
8. & Rearing net & 10 & 2000 & 100 \\
9. & Bambii & 20 & 500 & \\
10. & Miscellaneous & & 65,500 & 8800 \\
\hline
\end{tabular}

Source: Collected and computed by researcher from field, 2019 
Table 5. Annual Expenditure on Silk Worm Rearing from 1 Acre of Som Land.

\begin{tabular}{|c|c|c|c|c|c|c|}
\hline SI No & Particulars & Input & Man days & Rate (Rs.) & Amount (Rs.) & Remarks \\
\hline 1. & Depreciation (initial investment) & & & & 8800 & \\
\hline 2. & Interest on initial Investment & & & $8 \%$ pa & 1752 & \\
\hline 3. & Production of som leaf & & & $300 \mathrm{~kg}$ & 15416 & \\
\hline 4. & Bleaching powder & $12 \mathrm{~kg}$ & & 20 & 240 & \\
\hline 5. & Lime & $20 \mathrm{~kg}$ & & 7 & 140 & \\
\hline 6. & DFL for 2 seasons & 1000 & & 6.5 & 6500 & \\
\hline 7. & Labour for silkworm Rearing & & 120 & 180 & 21600 & \\
\hline & Total $=$ & & 120 & & 55,448 & \\
\hline
\end{tabular}

Source: Collected and computed by researcher from field, 2019

1. Profit with labour $=$ Rs. $58,552 /-$

2. Profit with family labour $=$ Rs. $83,392 /-$

3. Cost benefit ratio with labour $=1: 1.95$

4. Cost benefit ratio without labour: 1: 37

Table 6. Annual Profit from 1 Acre of Som Land.

\begin{tabular}{|c|c|c|c|c|c|}
\hline SI & Item & Quantity & Rate (Rs.) & Amount (Rs.) & Remarks \\
\hline 1. & Cocoon harvest at 60 nos./dfl & 60,000 & & & \\
\hline 2. & Sale of cocoon & 57,000 & 2 & $1,14,000$ & \\
\hline 3. & $5 \%$ damage cocoon & & & 500 & \\
\hline 4. & Total gross income & & & 114,500 & \\
\hline 5. & Total expenditure & & & 55,448 & \\
\hline 6. & Net profit & & & 58,552 & \\
\hline
\end{tabular}

Source: Collected from the field, 2019

\subsection{Impact of Muga Rearing on Livelihood}

The Handloom Textile and Sericulture Department, Govt. of Assam has launched Integrated Sericulture Development Project (ISDP) to popularize Muga rearing in the state particularly in the Brahmaputra valley of Assam [17].

North-East Region Textile Promotion scheme has contributed to livelihood opportunities and natural resource management initiative to the local community in the Brahmaputra valley in different way. The community has been benefitting from Muga rearing a fee that is paid by govt. under the scheme for the lease of land. About 1 hectare of land from each household have been leased at a fee of Rs. 94,000 per year. Over and above the community individually receives amounts ranging between Rs. 2000 - Rs. 3000 per year as bed charges (local accommodation) paid by the tourist/researcher who visits the area to explore Muga rearing culture. The community uses these earnings to support different community livelihood initiatives such as the provide money to self-help group, construction of schools, community houses, roads and expanses for community festivals.

Eco-friendly accommodation that has been developed in the region pays monthly salaries to local community who serve in the muga farm. Individual households benefit from the sale of muga cocoon, muga cloth and the different organic food stuff that are sold to individual and tourists. Earnings received from muga rearing are used in various ways, including purchase of livestock; land as well other necessary item, initiatives that are contributing towards livelihood in general and local food security in specific.

\subsection{Impact on Infrastructural Development}

The community reside in the Brahmaputra valley benefitting from improved infrastructural systems. These include better road network and other facilities such as drinking water, cleanness, school, medical facilities and so on. The all-weather road has improved community accesses to outside markets. To increase som plantation for the muga rearing the community constructed eleven small barrages on the different tributaries and planted som (Machilus bombycina). Community contact to the outside world has improved following access to electricity and telephone line provided by the govt.

More benefits to the local community come in a form of contribution from the department of Sericulture, Government of Assam. The sericulture department has been involved in the establishment of som plantaion and also facilitated negotiations between the community and govt. through workshops and exposure tours, helped to build trust for the initiative among the members of the community. The major investment of muga earnings is used for livelihood because there is no other foremost means of income generation in brahmaputra valley. Following exposure tours and consultative meetings local members have identified various forums for sharing information on technological innovations of muga rearing and possible funding.

Despite the different gains, reports from consultative meetings point to negative effects of muga rearing on livelihood. It is clear, for instance, that only a few members and/or institutions benefit. While the 'empowered few' help to mobilize locally available resources and create awareness among the rest of the members to participate in muga farming initiatives, the same members marginalize the rest of the community in benefiting from muga related gains. 


\section{Impacts on Environment Conservation}

Impacts on natural resource management on muga rearing initiatives has made positive impact on natural resource management and environment conservation. This is primarily because of national policy to integrate the initiatives with resource management and conservation. Conservation is still being influenced by the premise that any lifeform needs to be protected to avoid overutilization and/or through competition with nature. Despite this orthodox practice, there is evidence that the numbers of plants and animal species have either remained stable or increased due to som plantation. Massive plantation of som tree under the scheme has contributed to retaining congenial environment that improves the biodiversity in the area. The number of White Winged Wood Duck (cairina scutulata) a critically endangered bird species found in Brahmaputra valley stands at 424 numbers having risen from almost few at the time of conservation efforts. Following exposure tours, the community has expressed interest to introduce sustainable tourism practices and organic farming to reduce more threat to environment.

\section{Conclusions}

This paper has established how pilot North East Region Textile Promotion scheme have changed local practices and attitudes towards muga rearing and marketing of finished product. The impacts that include accumulation of savings by individuals are leading to social differentiation beyond traditional realms further marginalizing the already impoverished groups/individuals at the expense of the elite. Young well-to-do local who are increasingly controlling power in the community following their exposure to the outside world and the wealth they have accumulated, are eroding long-established settings. This new form of marginalization has to be addressed, especially through empowerment of individuals and are motivated to actively participate in emerging livelihood options.

\section{Acknowledgements}

I take the opportunity to express my deep gratitude and acknowledgement to ICSSR (Indian Council of Social Science Research) New Delhi, induce me to pursue the present research. I am also thankful to Prof. Chandan Goswami, Head, Department of Business Administration, Tezpur University for his immodest guidance in preparation and completion of this manuscript.

\section{References}

[1] Ahmed RZ, Choudhury SN, Bhattacharya PR (1998) Variation in cocoon characteristics of muga silkworm (Antheraea assama West wood) reared in som (Persea bombycina Kost) collected from different places of Upper Assam, India. Sericologia 38: 699-702.
[2] Barah A, Isa MD, Devnath M, Samson MV (1992) A new host plant of the muga silkworm, Antheraea assama Ww. Sericologia 32: 529-530.

[3] Bhattacharya A, Saikia SK, Goswami D (1993) Scientific inference to the traditional muga rearing. Indian Silk 32: 3541.

[4] Choudhury SN (1981) Mega Silk Industry, Directorate of Sericulture and Weaving, Govt. of Assam, Gauhati, Assam, India, pp 1-33.

[5] Das BC, Prasad DN, Sikdar AK (1970) Colchicines induced tetraploid of mulberry. Caryologia 23: 289-293.

[6] Hazarika R, Hazarika LK, Kataky A, Kataky JCS, Hazarika AK, Deka PC (1996) Association of morphological and biochemical characters of Machilus bombycina with the feeding behaviour of Antheraea assama. Sericologia 36: 511518 .

[7] Paliwal DP, Das PK (1989) Nodal and petiolar organization in the food plants of muga silkworm - A comparative analysis. Sericologia 29: 559-563.

[8] Raja Ram (1998) Sprouting behaviour of Som. Indian Silk 8: 21-22.

[9] Sengupta AK, Yadav YS, Ram R, Das R, Devnath M, Basumatary BK (1993) Genetic diversity in muga host plant. Indian Silk 2: 28-33.

[10] Siddiqui AA, Lal B, Bhattacharya A, Das K (2000) Nutritional status in morpho-variants of Som. Indian Silk 2: 28-33.

[11] Saikia. M, Ghosh. K and Peigler. R (2016). "Factors affecting on quality muga silkworm (Antheraeaassamensis Helfer) seed crop production: A review.” JEZS, Vol 4, Issue 6, pp 806-810.

[12] Srivastava A, Singh K, Das PK, Siddqui AA, Raghuvanshi SS (2000) Germination and seedling growth in Machilus bombycina King morphotypes. Sericologia 40: 503-507.

[13] Thangavelu K, Tikader A, Sen AK (2005) Strategies for conservation of muga host plant genetic resources. Present status and constraints of muga silkworm host plant germplasm conservation. In proceedings: Strategies for maintenance of non-mulberry silkworm and host plant germplasm held at Central Muga Eri Research \& Training Institute, Lahdoigarh, Jorhat, Assam, India on March 10 -11, pp 37-47.

[14] Tikader A, Thangavelu K (2006) Grafting performance of some mulberry germplasm collected through exploration. Indian J Forestry 29: 69-71.

[15] Tikader A, Dandin SB (2007) Pre-breeding efforts to utilize two wild Morus species. Cur Sci 92: 1729-1733.

[16] Tikader A, Kamble CK (2008a) Mulberry wild species in India and their use in crop improvement-A review. Aust J Crop Sci 2: 64-72.

[17] Tikader A, Kamble CK (2010) Seri-biodiversity status with reference to the host plants in India. Asian Aust J Plant Sci Biotech 4: 1-11.

[18] Tikader A, Gogoi AK, Pachuau L, (2011a) Muga culture: the rich tradition of Assam. Indian Silk 2: 18-20.

[19] Phukan. R., (2012). "Muga silk industry of Assam its historical perspectives". Global Journal of Human Social Science History \& Anthropology". Volume 12 Issue 9, pp 5-8. 
[20] De and Das (2007). "Ericulture as a Remedy of Rural Poverty in Assam: A Micro Level Study in Barpeta District." Munich Personal RePEc Archive, and can be retrieved at Online at http://mpra.ub.unimuenchen.de/6291/pp 2-22. Assessed on $26 / 06 / 2017$ at $12: 30 \mathrm{pm}$.
[21] Chakraborty. R, Dutta. P and Ghosh. J. (2010). "Sericulture and Traditional Craft of Silk weaving in Assam. "Indian journal of Traditional Knowledge, Vol. 9, Issue No. 2, pp 378385 . 